Research Article

\title{
Prediction of the Bending Strength of Boltless Steel Connections in Storage Pallet Racks: An Integrated Experimental-FEM-SVM Methodology
}

\author{
Zhi-Jun Lyu $\mathbb{D}^{1,2}$ PeiCai Zhao ${ }^{1}{ }^{1,2}{ }^{1,2}$ Qi Lu, ${ }^{3}$ Qian Xiang, ${ }^{1,2}$ and HongLiang Li $^{2}$ \\ ${ }^{1}$ College of Mechanical Engineering, Donghua University, Shanghai 201620, China \\ ${ }^{2}$ Shanghai Engineering Research Center of Storage \& Logistics Equipment, Shanghai 201611, China \\ ${ }^{3}$ SAIC General Motors, Shanghai 201206, China
}

Correspondence should be addressed to Zhi-Jun Lyu; lvzj@dhu.edu.cn and PeiCai Zhao; 852692515@qq.com

Received 6 February 2020; Revised 16 July 2020; Accepted 9 September 2020; Published 22 October 2020

Academic Editor: Maksym Grzywinski

Copyright ( 2020 Zhi-Jun Lyu et al. This is an open access article distributed under the Creative Commons Attribution License, which permits unrestricted use, distribution, and reproduction in any medium, provided the original work is properly cited.

Due to many differences in the material, geometry, and assembly method of the commercially available beam-end-connectors in steel storage pallet racks (SPR), no common numerical model has been universally accepted to accurately predict the $M-\theta$ behavior of complex semirigid connections so far. Despite the fact that the finite element method (FEM) and physical experiment have been used to obtain the mechanical performance of beam-to-column connections (BCCs), those methods have the disadvantages of high computational complexity and test cost. Taking, for example, the boltless steel connections, this paper proposes a data-driven simulation model (DDSM) that combines the experimental test, FEM, and support vector machine (SVM) techniques to determine the bending strength of BCCs by means of data mining from the engineering database. First, a threedimensional (3D) finite element (FE) model was generated and calibrated against the experimental results. Subsequently, the validated FE model was further extended to perform parametric analysis and enrich the engineering case base of structural characterization of BCCs. Based on the $M-\theta$ curve of the FE simulation, support vector machines (SVMs) were trained to predict the flexural rigidity of beam-to-column joints. The predictive power of the SVM algorithms is estimated by comparison with traditional ANN models via the root mean square error (RMSE), the mean absolute percentage error (MAPE), and the correlation coefficient R. The results obtained indicate that the SVM algorithms slightly outperform the ANN algorithms, although both of them are in good agreement with FEM and physical test. From the point of view of engineering application, DDM is able to provide much more effective help for structural engineers to make rapid decisions on steel members design.

\section{Introduction}

With the rapid advancement of e-commerce, automated storage and retrieval systems (AS/RS) have been so widely applied in China that high-rise steel storage pallet racks (SPR) have exhibited an explosive growth in production and logistics system (Figure 1). Acting as one of the most important infrastructures for AS/RS, structural design for SPR needs the elaborate decision-making between structural systems and a variety of cold-formed steel members in such a way that the stability and safety behave as intended by the designer and satisfies the constraints imposed by capital investment, environment, and so on. Opposite to traditional civil engineering structures, the material of steel members in storage pallet racking is thin and lightweight while the racking system itself can usually carry live load many times larger than the dead load with an extraordinary height.

Of all the members in the SPR, the beam-to-column connections (BCCs) constitute the most critical part of the assembly which largely determines the overall stability of SPR in the down-aisle direction [1]. The details of the boltless BCCs with the three rivets mostly used in industrial racking system are shown as an example in Figure 2. Due to the great variety of connector types and connected members, a generalized analytical evaluation of the connection mechanical properties still appears to be very difficult [2]. One 


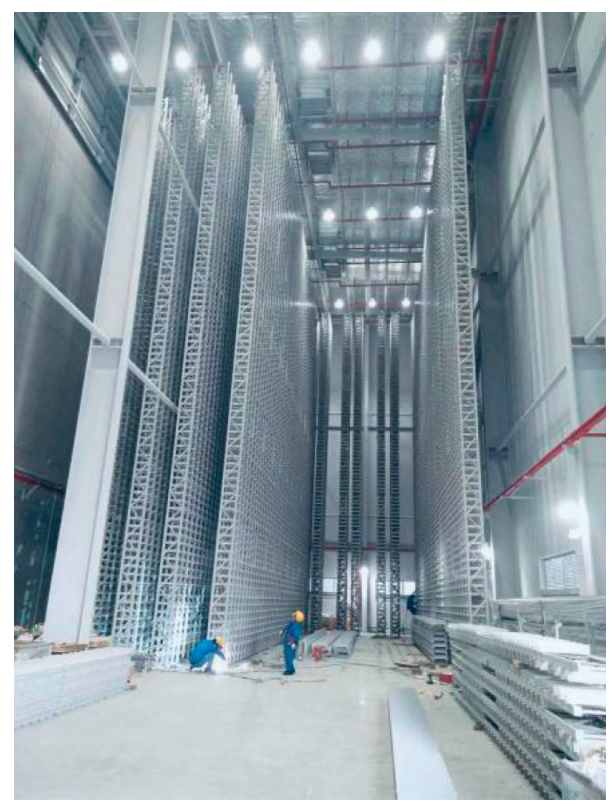

FIgURE 1: High-rise steel pallet racks under construction in China.

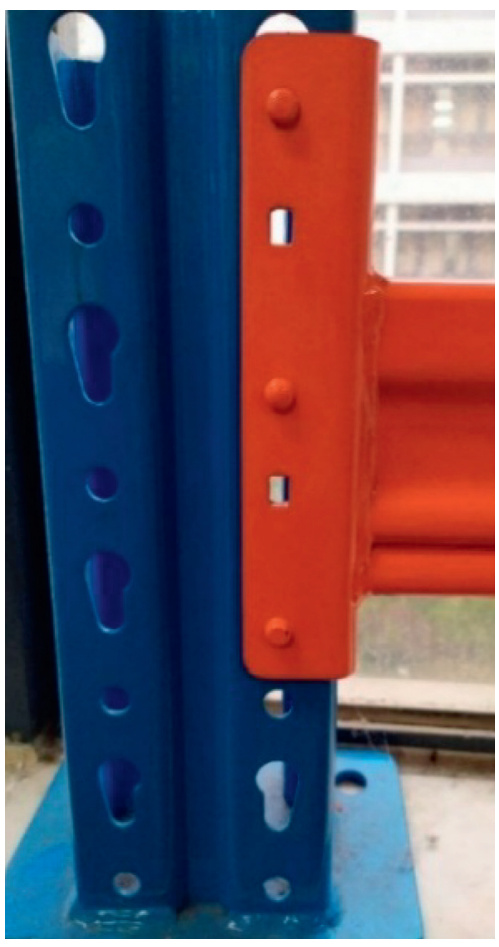

(a)
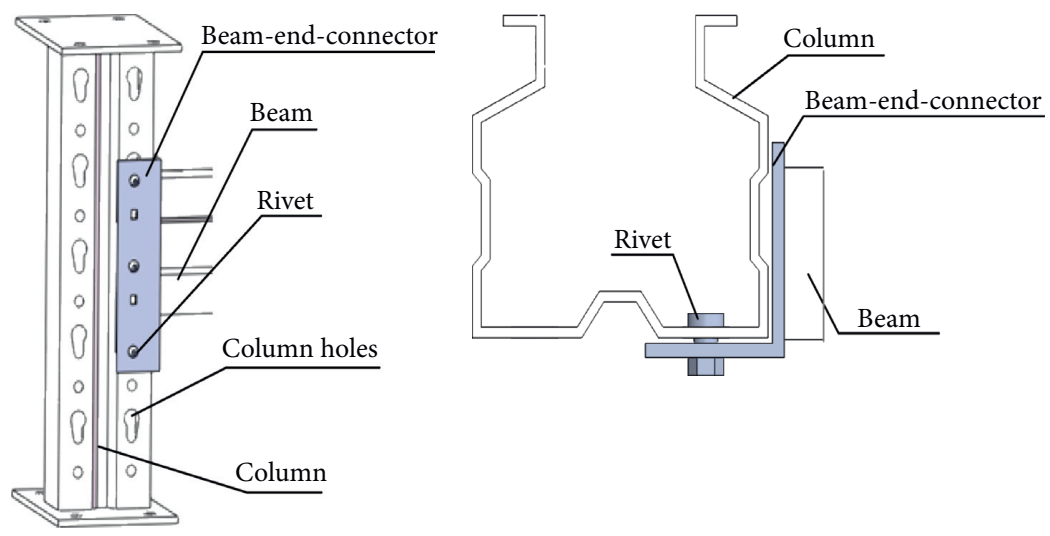

Figure 2: Details of SPR BCC. (a) Physical map. (b) Top view. (c) Isometric drawing.

of main reasons for this is that the typical boltless steel connections are essentially called "semirigid" or "partialstrength" structure representing a strong nonlinear behavior [3]. Therefore, the most recent design codes, such as those of the EN 15512 [4], RMI [5], and AS4084 [6], recommend physical experiment method of the testing results to assess the moment-rotation $(M-\theta)$ behavior of any SPR BCC. Numerous studies in the last few years are available on the experimental testing of SPR BCCs [7-11]. Apparently, these investigations, dependent on experimental results, are relatively accurate and reliable but their arrangements are too expensive, and operations are too complicated to be utilized in industrial production on a large scale. On the other hand, the possibility of random or systematic errors in the experimental investigations and the diversity of beam-end-connectors also directed researchers towards the finite element (FE) modeling 
of connections [2, 12]. FE modeling, which was made by using different analysis software, has proven itself to be a powerful tool to gain a more predictable performance of the connections and the effects of various parameters on the overall performance of SPR. Furthermore, a suitable solution was proposed to derive a particular uniform $M-\theta$ relationship for each connection type on the basis of BCCs geometric parameters through experimental investigations and finite element (FE) modeling [13]. From analytic point of view, Zhao et al. and Gusella et al. proposed a mechanical model based on the component method to predict the initial rotational stiffness of beam-to-upright connections [14, 15]. Those analytical models are based on physical knowledge of stability mechanics, which not only are very appealing but also give a thorough insight into the deformation mechanism of multiple components. However, to cope with the inherent complexity of structural mechanics, some assumptions have to be introduced into these models, among which, the assembly relationship of the beam-to-column joints has not specially been addressed in previous studies. This may ultimately affect the prediction accuracy of analytical models and then result in unexpected deviation from physical tests. The increasing demands for cold-formed thin-walled steel in modern industry need to explore more reliable methods of accurate prediction of the behavior of storage racks, which have a wide range of adaptability and operational convenience in engineering design. The proliferation of industrial "big data" has created many exciting opportunities for those working in various fields such as science, engineering, and business. The machine learning (ML) and data mining (DM) from industrial big data have been rapidly developed as new disciplines of computer science and engineering application $[16,17]$. It has been gradually realized that those data from engineering experiments and analysis not only can be used for the engineering practice, but also have the potential to provide insight and knowledge for the designer to improve the construction quality itself. The data-driven approaches focus on analysis and discovery of the potential pattern of design process and can realize precise prediction of complex engineering problems, usually including some metaheuristic optimization algorithms such as the genetic algorithm and particle swarm optimization, artificial neural network (ANN), support vector machines, and Bayesian models [18]. Within the constructional steel fields, the advantage of an ANN was used to propose an intelligent finite element for viscoelastic material behavior in [19]; Shah et al. [2] also proposed a hybrid intelligence model based on linear genetic programming (LGP), artificial neural networks (ANNs), and adaptive neuro-fuzzy inference system (ANFIS) to predict the moment-rotation $(M-\theta)$ behavior of boltless steel connections [20].

In recent years, a variety of machine learning methods have been applied on a large scale in the modern industrial and civil engineering field. Among them, convolutional neural network (CNN) is one of the representatives of deep learning algorithm, which is suitable for multipixel and audio processing. Cha et al. [21] and Wang and Cha [22] used these novel deep learning methods for damage detection in structural-health monitoring for civil structures.
In addition, Santos et al. [23] compared four kernel-based algorithms for damage detection under varying operational and environmental conditions, namely, based on one-class support vector machine, support vector data description, kernel principal component analysis, and greedy kernel principal component analysis. Langone et al. [24] came up with a technique called adaptive kernel spectral clustering (AKSC) which unifies the data normalization and damage detection steps. Inspired by the idea of unsupervised feature learning that uses artificial intelligence techniques to learn features from raw data, a two-stage learning method is proposed, with Moving Kernel Principal Component Analysis (MKPCA) and Nyström methods, by Ghiasi and Ghasemi [25] for intelligent health monitoring of civil engineering structures. Besides, support vector machines (SVMs) are also receiving increasing attention in different application domains for which artificial neural networks (ANNs) have had a prominent role, due to their many attractive features and promising empirical performance. This systematic approach, motivated by statistical learning theory, led to a class of algorithms characterized by the use of kernels, the absence of local examples, the sparseness of the solution, and the capacity control obtained by acting on the margin. Unlike traditional ANN models, SVM models are based on the principle of structure risk minimization (SRM), which equips the latter with greater potential to generalize. Since the foundation of the SVMs paradigm was laid down by Vapnik in mid-1998 [26], applications in many engineering fields have emerged, such as architecture [27], communication system [28], geology [29], and even financial management [30]. However, reports about which SVMs are used for predicting the $M-\theta$ behavior of SPR BCCs have not been seen so far.

Taking the riveted BCCs as our research object, we present a novel data-driven model, using an integrated experimentalFEM-SVM methodology to overcome many difficulties associated with the mechanical performance of semirigid beam-to-upright joint modeling, which is the main contribution of this paper. The objective of data-driven based predictive models is the development of enabling tools for designers to make rapid and effective decision when big datasets are available on prediction and reasonable number of predictors. Compared with existing references, the obvious distinctions of our work lie in the fact that the finite element simulation data based on physical test are utilized to train SVM model and predict the bending strength of the complex boltless steel connections with data mining method. The results have undergone comparative analysis with those of the traditional FEM and ANN. The preliminary investigation demonstrates that the data-driven models have a reasonably good accuracy in most of the cases and are more suitable for the nonlinear mechanical behaviors. The outline of the remaining content of this paper is as follows. Section 2 briefly describes data-driven model framework and integrated methodology. Based on the data from physical performance tests of BCCs, Section 3 develops a finite element model to exactly simulate the flexural behavior under monotonic loads. Section 4 introduces the SVM regression algorithm and data mining process. The results and discussion of the case study 
are presented in Section 5. Finally, the conclusions and future work are summarized in Section 6.

\section{Data-Driven Based Methodology Framework}

Generally speaking, the current models available to solve the mechanical performance problem of the SPR BCCs can be mainly categorized into two types: physical experiment based analytical models and FE based numerical model. However, the use of the two techniques for analyzing this wide range of beam-to-upright assembly in massive engineering practices could be inappropriate due to the great amount of time and economic resources required. The methodology proposed in our paper is based on a hybrid approach of experimental, numerical (finite element method), and machine learning (support vector machines) techniques, which allows the obtainment of computational efficient results for various design solutions to make rapid and accurate evaluation. As shown in Figure 3, the datadriven modeling framework includes three stages, and the general task in each stage is described as follows.

\section{Stage I: Data acquisition}

The task of this stage is to collect and transform the data from the beam-to-column physical experiment and finite element simulation into engineering database. Because the physical experiments are so costly that volume of real dataset is relatively limited, the finite element simulation is employed to expand engineering data as machine learning required. On the basis of the test data, the finite element model in the commercial software ANSYS is repeatedly calibrated and validated in order to exactly simulate the blending process of the cantilever beam experiment; then, using the so-called virtual testing method, the different rotational stiffness from finite element simulation for the existing joint solutions is obtained instead of the real physical test. Finally, the substantial data such as the geometric features, assembly relationship, and corresponding mechanical behavior on the diverse BCC joints are stored in engineering analysis database.

Stage II: Machine learning

This stage is the core module of data-driven modeling which can cover the full machine learning pipeline from data processing to result evaluation. In most cases, those modeling data from the engineering database fall within different ranges. It is highly essential to preprocess the input data before applying them to the machine learning models, so as not to affect the obtained results. On the other hand, these raw data and engineered features probably have a large number of independent or redundant variables, which often make models more complex and incomprehensible. There are two main dimensionality reduction methods for data: one is to extract the main features of the data by destroying the original structure of the data. The other is to conduct correlation analysis on the data and select the attributes of the data according to certain rules to

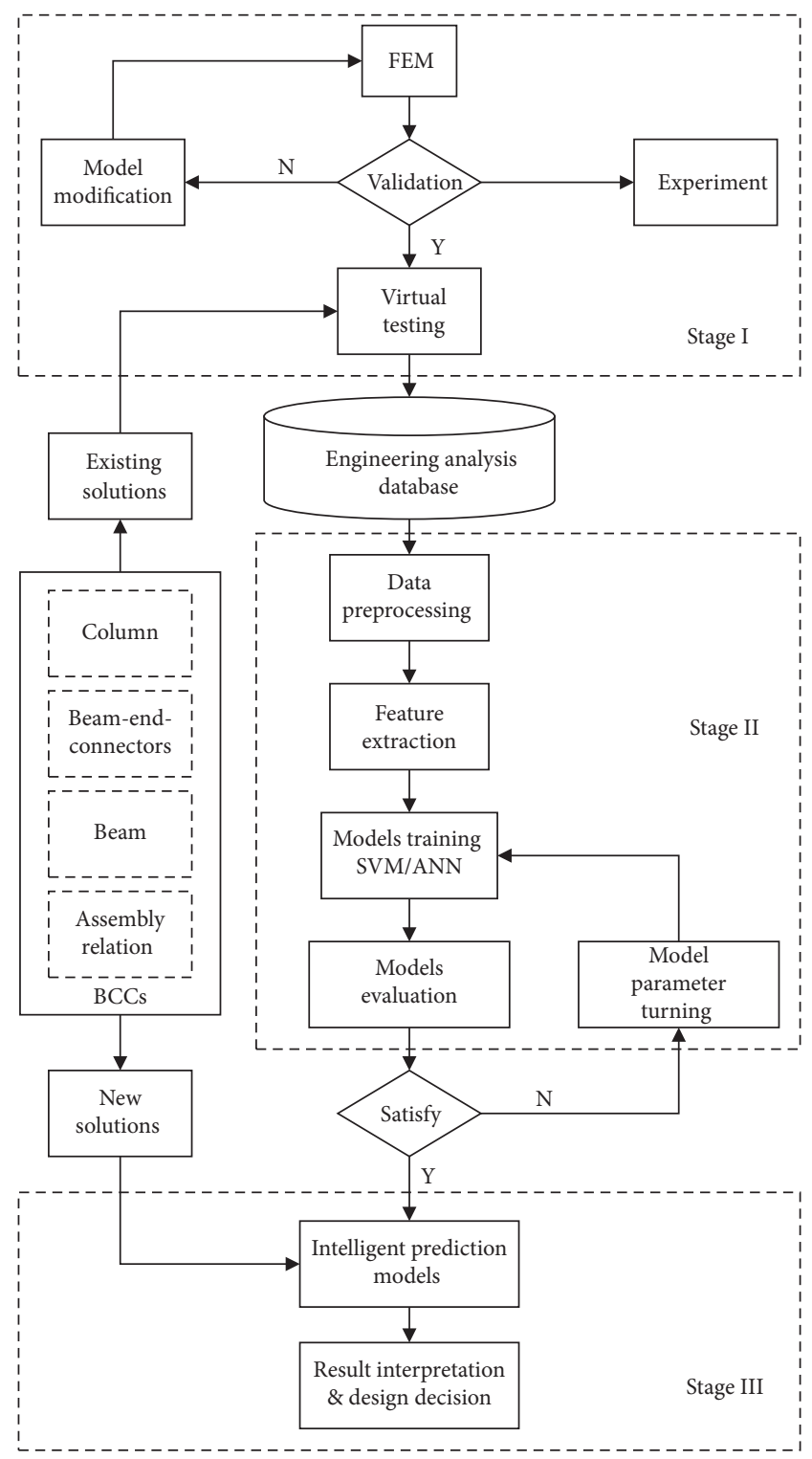

Figure 3: Methodology framework.

achieve the purpose of dimensionality reduction. Kernel methods belonging to the first type, such as the kernel principal component analysis (KPCA), have the ability to find nonlinear patterns from the data while keeping the computational elegance of matrix algebra, but they often take up a lot of memory and the calculation is more complicated [31]. Here, the correlation coefficient after Pearson R falls into the second type as an easier feature extraction method is used to reduce the data dimensionality and improve the generalization performance of a predictive model. In the model training, the normalized dataset is randomly divided into separate train and test sets; on the basis of those data, the control parameters of the SVM model are continuously adjusted and optimized through iterative loop mode until the predictive accuracy satisfies the need of engineering practice as a whole. 
Stage III: Design decision

Once the predictive model is trained well, new design solutions for the BCC joint are input into it one by one, and their mechanical performance can be quickly obtained so that structural engineers can make more reasonable decisions.

Unlike the existing programs and methods $[2,14,32,33]$, the merits of data-driven model framework lie in the following:

(i) SVM/ANN is a self-adaptive and data-driven method in nature, so there is no need to make some rigorous assumptions about the statistical distribution on real engineering data.

(ii) SVMs are good at handling data with much more features than samples, which makes it more accurate for modeling complex data patterns, as opposed to traditional modeling approaches based on a large amount of test data.

(iii) Along with the growth of engineering data, the proposed framework is very expandable and has the capability of improving prediction accuracy by system self-learning.

(iv) Robust reasoning machine in the intelligent prediction model is utilized to optimize design parameters on the SPR BCCs as predictive model calculating without consideration of the potential rule collision from explicit design knowledge.

\section{Experiments Based Finite Element Simulation}

The flexural tests on the different BCCs are the foundation of analyzing the mechanical performance of boltless connections. On the basis of the physical test, a refined finite element model on SPR BCCs was built to simulate the cantilever test process as accurate as possible in this section.

3.1. Experimental Program. The cantilever testing method is considered to be an efficient method to predict the strength characteristics of SPR BCCs [34], which can give a precise experimental evaluation of the flexural behavior of locally manufactured beam-to-column connections when subjected to increasing static hogging loading. In this method, both ends of the column are kept rigidly fixed. The end of the pallet beam attached to the end connector is inserted in the perforations at the center of the column, and the other end is left in cantilever. A lateral restraint is provided to prevent the twisting of the beam end, and the beam is left free to move in the loading direction. Loading should be applied $610 \mathrm{~mm}$ from the face of the column. The consequent displacement in the line of action of the applied load and/or the rotation near the connector is observed. The rotation is measured by either transducers or inclinometers.

3.1.1. Material Properties. The material properties of the column, beam, and beam-end-connector were obtained through the tensile coupon test and are given in Table 1. The test was conducted according to EN 15512 [4]. The standard specifies that the testing specimens for tensile test should be cut from the direction of rolling on samples of raw material coil, in accordance with EN 10002-1 [35].

3.1.2. Specimen Details. The specimens were distinguished by three different types of columns, four different beamend-connector thicknesses (Table 2, Figure 4), three different beam positions (Figure 5), three different clearances between the connectors and the column webs (Figure 5), and other characteristics (see Section 5). All the dimensions of the specimens are the measured values.

3.1.3. Testing Arrangement. Six groups of beam-to-columns chosen in pallet racking have been tested and analyzed from the existing experimental data which were collected from the Shanghai Jingxing Logistics Equipment Engineering Co., Ltd, China. The experiment setup and supporting systems are shown in Figure 6.

At the beginning of the test, an initial load $F$ of $10 \%$ of the expected failure load was preloaded at $400 \mathrm{~mm}$ from the beam flange surface to the column. The purpose is to make the rivets on the beam-end-connector fully contact the column grooves, then fix the components, and then unload. The measuring instrument was reset, and then the force $F$ was gradually increased to the maximum load value until the BCCs failed. During the test, load $F$ was measured by a load cell, and the vertical components of the displacements $d_{1}$ and $d_{2}$ at the loaded section were directly monitored by the linear variable displacement transducer (LVDT) of the testing machine. LVDTs and wire-actuated encoders were connected to a computer-aided data recording system and load cells.

\subsubsection{The Experimental Results and Moment-Rotation} Response. The stiffness of beam-to-column is obtained by moment-rotation $(M-\theta)$ curve. The rotation may be measured by displacement transducers bearing onto a plate tackwelded to the beam close to the connector, but with enough clearance to allow for connector distortion. The moment $M$ and rotation $\theta$ were calculated by the following equations:

$$
\begin{gathered}
M=b \cdot F, \\
\theta=\frac{d_{1}-d_{2}}{k},
\end{gathered}
$$

where $F$ is the loading; $b$ is the distance between the loading jack and the surface of the column, which is $400 \mathrm{~mm} ; d_{1}, d_{2}$ are the displacements; and $k$ is the distance between $d_{1}$ and $d_{2}$.

According to the code EN 15512 [4], the yield stress and thickness of the materials of the beam, upright and connector in Table 2 are used to calibrate the observed value of $M$ and $\theta$ of the test. The acquisition of stiffness requires an over coordinate origin line at the $M-\theta$ polynomial fitting curve (Figure 7), which, with the line of design moments $M_{t, \mathrm{Rd}}$, divides the test curve into two equal parts $\left(A_{1}\right.$ and $\left.A_{2}\right)$. Apparently, the bending strength of beam-to-column is determined by the slope of the line. 
TABLE 1: Material properties of the specimens.

\begin{tabular}{lcccc}
\hline Structural elements & Young's modulus $E(\mathrm{GPa})$ & Poisson's ratio $v$ & Yield strength $f_{y}\left(\mathrm{~N} / \mathrm{mm}^{2}\right)$ & Ultimate strength $f_{u}\left(\mathrm{~N} / \mathrm{mm}^{2}\right)$ \\
\hline Column & & & 376 & 562 \\
Beam & 210 & 0.3 & 348 & 496 \\
Beam-end-connector & & & 359 & 528 \\
\hline
\end{tabular}

TABle 2: Specimen from the columns, beams, and connectors.

\begin{tabular}{lcccc}
\hline Structural elements & Web length/beam width & Flange width/beam height & Mean thickness $t_{t, m}(\mathrm{~mm})$ & Mean yield strength $f_{y, m}\left(\mathrm{~N} / \mathrm{mm}^{2}\right)$ \\
\hline \multirow{2}{*}{ Column } & 94 & 77 & 2.023 & 339.8 \\
Beam & 100 & 100 & 2.055 & 375.8 \\
Connector & 48 & 100 & 1.51 & 348 \\
\hline
\end{tabular}

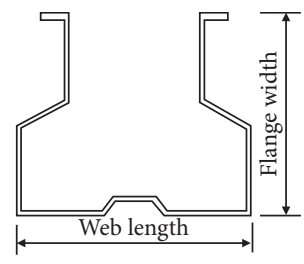

(a)

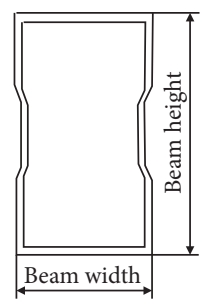

(b)

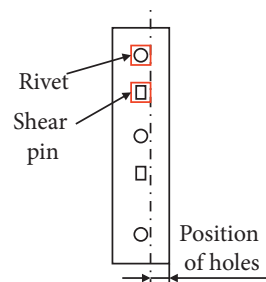

(c)

FIGURE 4: Cross section of the connection components. (a) Column. (b) Beam. (c) Beam-end-connector.

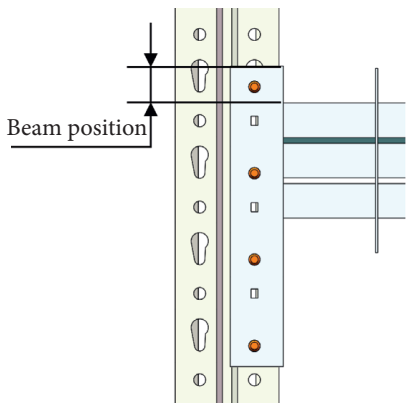

(a)

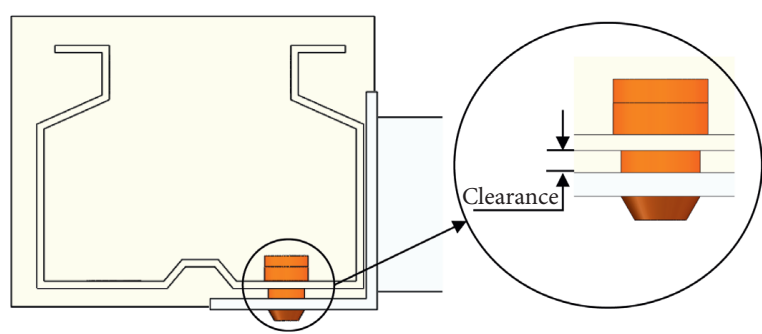

(b)

Figure 5: Assembly parameters. (a) Beam position of BCC. (b) Clearance of BCC.

3.2. Finite Element Simulation. The goal of the finite element (FE) model of the BCCs in our work is the flexibility to represent the complex cross-sectional geometry of the component and the ability to assign semirigid behavior to the seam and take into account the effects of local deformation, as well as flexural buckling of the ultimate bearing capacity of the structure. With reference to the finite element (FE) modeling of storage rack system [20], the commercial finite element software ANSYS R17 is used for the model development and analysis presented in this paper.

3.2.1. Establishment of Geometric Model. Firstly, the 3D models are established based on the real value of the tested samples using the SolidWorks software. It is noticed that the cross section and the hole setting are not simplified to ensure the accuracy of the finite element model, but the chamfer and fillet have been simplified accordingly. The beam and the measuring plate on the beam are welded in the actual test, so the beam and the measuring plate are integrally modeled during the three-dimensional modeling, as shown in Figure 8. Different finite element types in the ANSYS software package are used in the modeling of beams, columns, connectors, and rivets. Among them, SHELL163 (4node 3D elastic shell) was used to model beams, columns, and connectors. SOLID45 (8-node 3D structural solid) was used to model rivets and load plates. The spar elements carry only axial forces, and any shear on the interface between the connector and the column flange will be transferred through the friction allowed by the contact elements. Specific element characteristics are shown in Table 3.

3.2.2. Material Properties and Mesh. The materials on the tested samples were set as nonlinear steel for subsequent buckling analysis by the ANSYS Workbench with Structural Steel NL. The material properties of all the three components listed in Table 1 were imported to the FE model (FEM). 


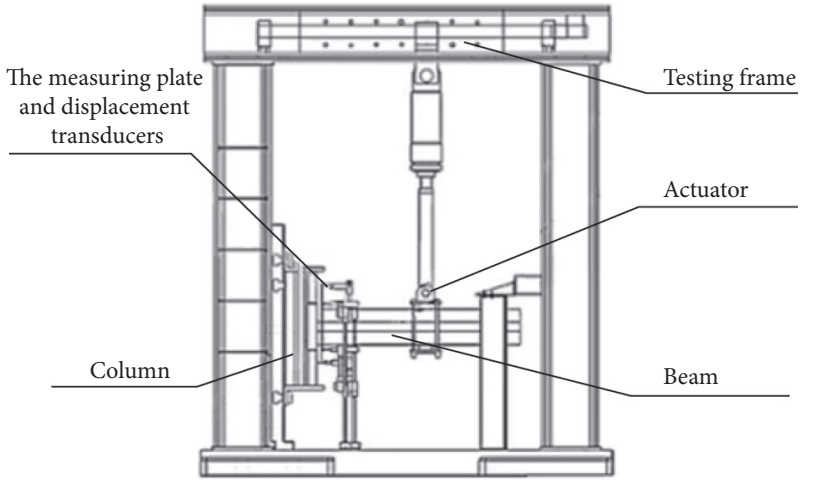

FigURE 6: Schematic diagram of test setup.

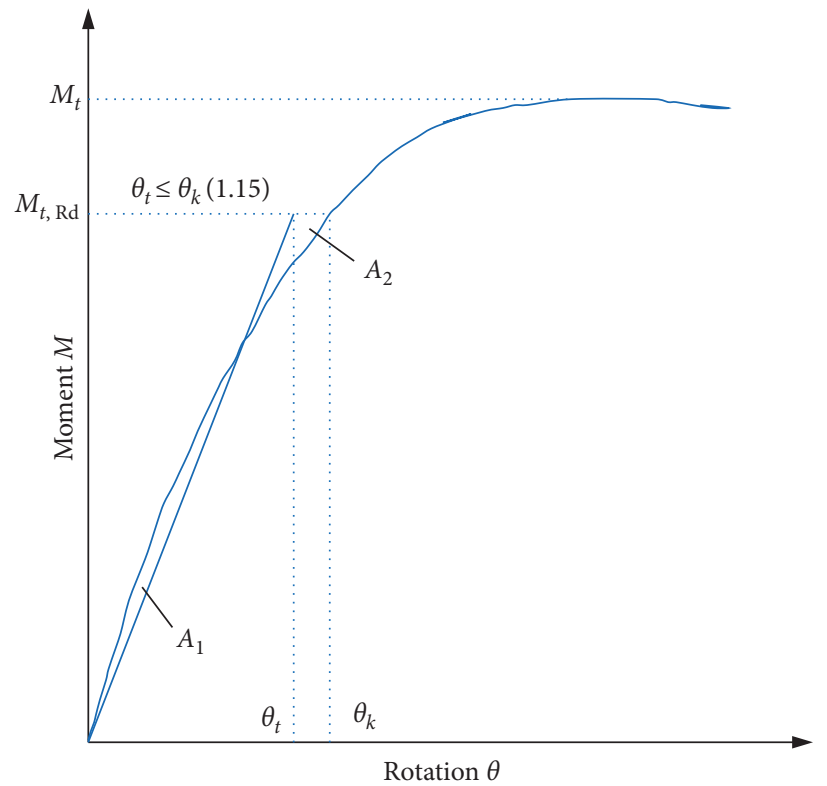

Figure 7: $M-\theta$ polynomial fitting curve for the typical riveted BCC.

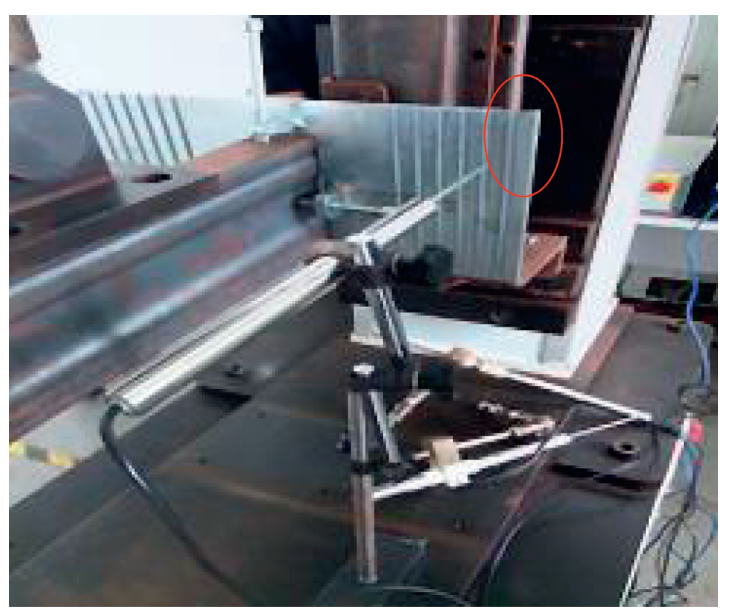

(a)

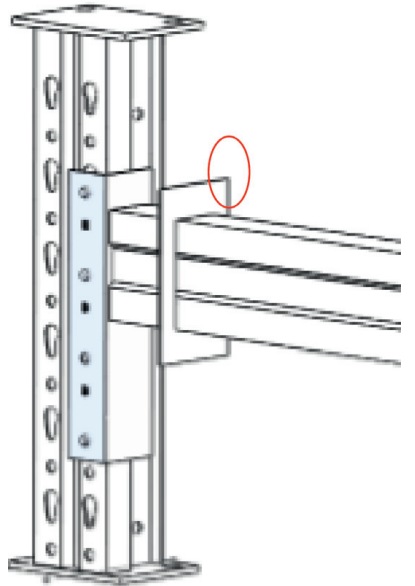

(b)

Figure 8: Measuring plate. 
TABLE 3: Element characteristics of SHELL163 and SOLID45.

\begin{tabular}{lcc}
\hline Name & SHELL163 & SOLID45 \\
\hline Position & Column, beam, connector & Rivet \\
Character & Elastic shell element & 3D solid structural unit \\
Node number & 4 & 8 \\
Nodal freedom & UX, UY, UZ and ROTX, ROTY, ROTZ & UX, UY, UZ \\
\hline
\end{tabular}

Meshing is the basis of finite element analysis. Reasonable meshing can reduce the use of computer memory, and the results are more accurate. Firstly, the 3D assembly model of beam-column joint is sliced in the geometry module, and the column, connector beam weldment, and rivet are manually split into three independent parts. Then the independent parts are from new part processed, and the model is divided into 20-node full hexahedron units. As the main structures for transmitting torque, the open hole parts of the upright posts, connectors, and rivet structures are more prone to deformation, so the grids of these parts are more finely divided. Numerical trials using different mesh sizes have shown that mesh size of $10 \mathrm{~mm}$ is more appropriate to achieve accurate results. After division, Figure 9 shows the meshing of the entire connection.

3.2.3. Surface Interaction. The beam-column joints are semirigid assemblies with welded and riveted components and different contact surfaces between members. The accuracy of simulation results will be affected by surface-to-surface contacts directly. Therefore, different contact settings are made for the contact surfaces that interfere when the beam-column joints are stressed. As shown in Figure 10, in the assembly of beam-column joints, except for the welded beams and mounting plates, the mounting plates and rivets with interference fit are not required to be set as a whole by default. The contact surface of each rivet matching with the column hole is shown in Figure 10(a). The contact surface on which the hanging plate and the column may deform under stress is shown in Figure 10(b). The contact between the rivet and the column hole is set to friction so that the connection between the beam and the column is loose and meets the semirigid property of the BCCs. Frictional parameters were set at 0.3 by referring to GB 50017-2003 steel structure design specification. During the simulation process, the contact surface between the column and the connector may be deformed without interfering with each other; in order to ensure the simulation accuracy, the contact surface parameters need to be set to the "adjust to touch" option (contact only).

3.2.4. Loading and Boundary Conditions. In the experimental setup, the bolt-type fixed connection was used to completely restrain the six degrees of freedom of the column. Further, the fixed frame was used to limit the displacement of the beam perpendicular to the column. Therefore, similar boundary conditions were applied to the end of the column and the beam. For the test setup, a force loading was applied to the beam at a distance of $400 \mathrm{~mm}$ from the contact surface of the column and the connector. Similar loading protocol was adopted for the FE analysis. The load was applied to the top of the beam which causes compression in the top of the beam-end-connector and tension at the bottom. All node displacements of the bottom plates on column and side plates on beam in the negative $Y$ axis have been set to zero (Figure 11). Two probe points were placed on the top flanges of the beams on either side to observe the deflection in the beams. The stiffness of FEM simulation could be obtained by $M-\theta$ curve as shown in Figure 7.

3.2.5. Validation of the FE Model. The simulation results of beam-column joints when the load $F$ reaches $1000 \mathrm{~N}$ are shown in Figure 12. Referring to the method of obtaining stiffness value of beam-column joint in mechanical performance test, the four measuring points are, respectively, placed at four corners of beam measuring plate, corresponding to displacement sensors in mechanical performance test. Among them, the average value of the results of the two measuring points $A$ and $B$ is taken as the value of $d_{1}$ in formula (2), the average value of the results of the two measuring points $C$ and point $D$ is taken as the value of $d_{2}$ in formula (2), the $M$ and $\theta$ values under the corresponding loads are obtained according to the calculation method in Section 3.1, and the $M-\theta$ curve of the finite element model is obtained by curve-fitting finally.

A comparison of the $M-\theta$ graphs plotted for the experimental and finite element studies is provided in Figures 13(a)-13(d). Four specimens with varying column thickness values and column cross-sectional areas were compared to illustrate the agreement between the experimental and FE analysis results. It was found that the stiffness of the specimens was on the verge of that in the experimental result even though the ultimate moment capacity of the connection obtained from the FE model for specimen was slightly higher than that from the experiments. This is because the imperfections from material and fabrication are not considered by the FE model [1]. Moreover, due to the assembly defect between rivets and columns and the small applied load at the initial stage of the test, there is a deviation between the two $M-\theta$ curves near the origin. According to formulas (2) and (3), the stiffness values of $M-\theta$ are calculated, and it is found that the stiffness values are not much different, and the average error of the four groups is about $4.6 \%$.

During the mechanical performance test and finite element simulation, three failure modes of beam-column joints were observed. The failure modes are shown in Table 4: (i) yielding of the beam-end-connectors, (ii) tearing of the column material, especially the holes, and (iii) fracture or yielding of the rivets. When the beam-column joint is under 


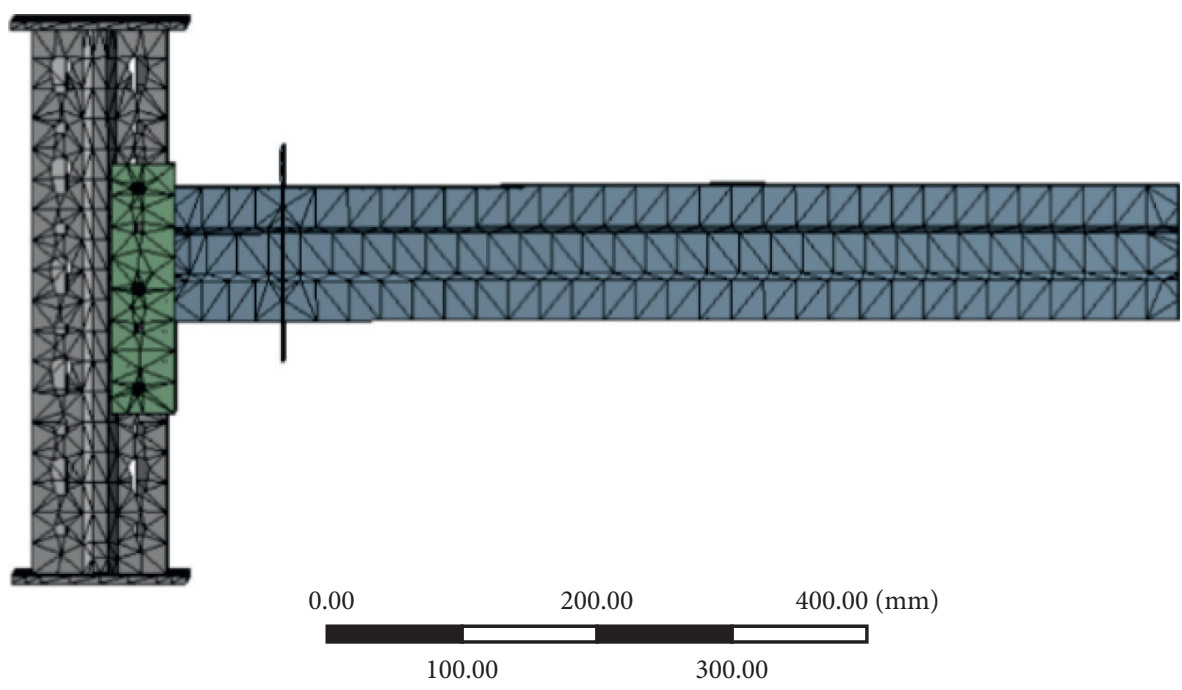

Figure 9: Diagram of mesh.

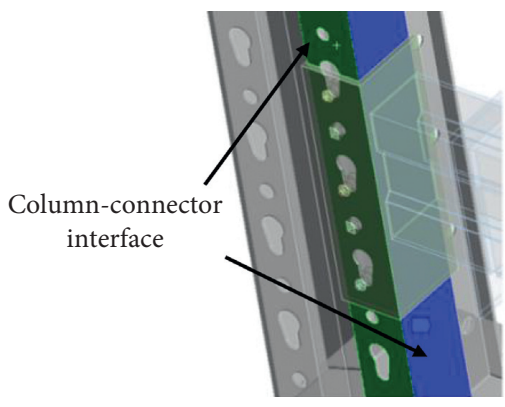

(a)

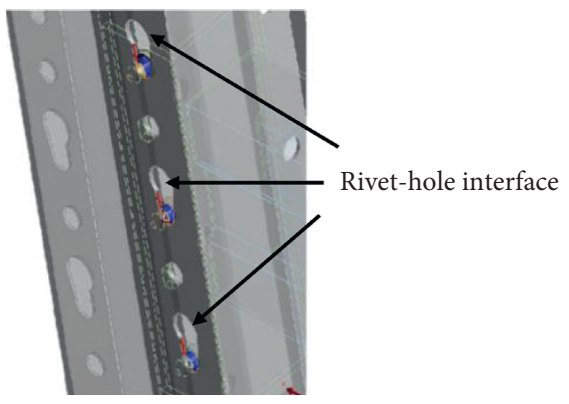

(b)

FIGURE 10: (a) The interaction between surface of column and surface of beam-end-connectors. (b) The interaction between surface of rivet and holes of column.

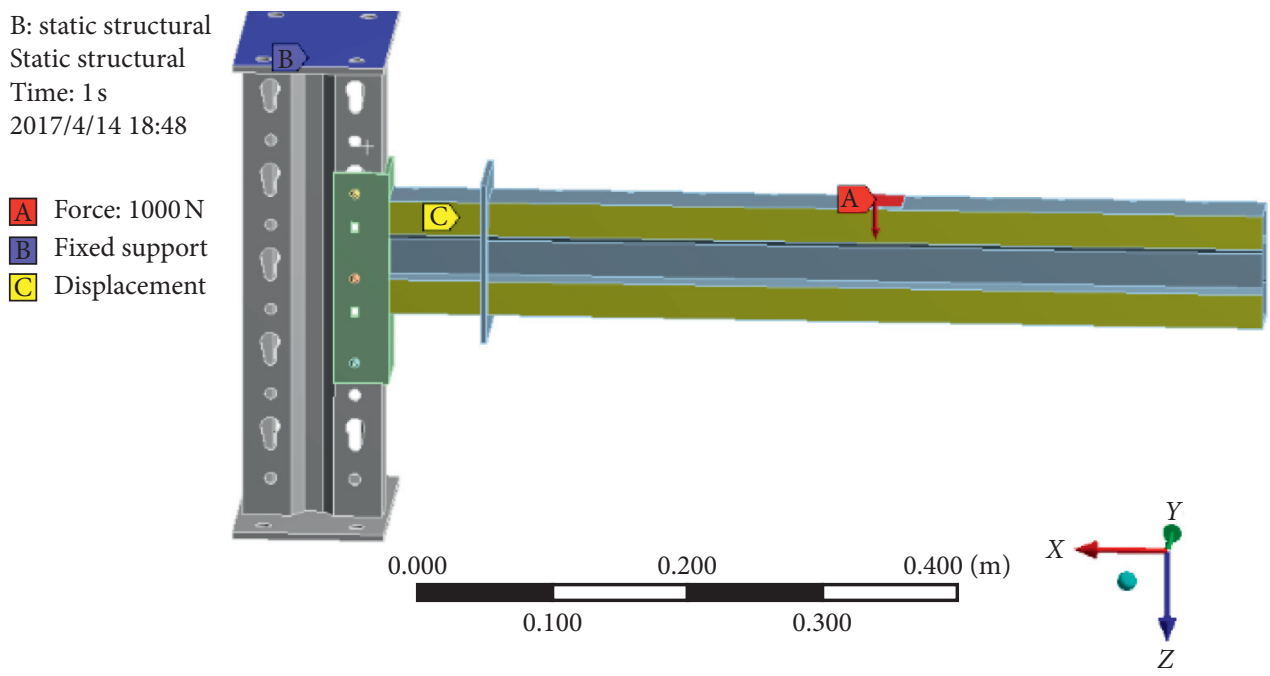

FIgURE 11: Boundary condition and loading.

compression, the rivet will bear the shear force opposite to the direction of the connector and the column, resulting in plastic deformation. The three simulated failure modes basically agree with the mechanical performance test, which verifies the validity of the simulation results. It is shown from the above diagrams that the FE model can predict the 
Time: 1

2020/9/6 16:52
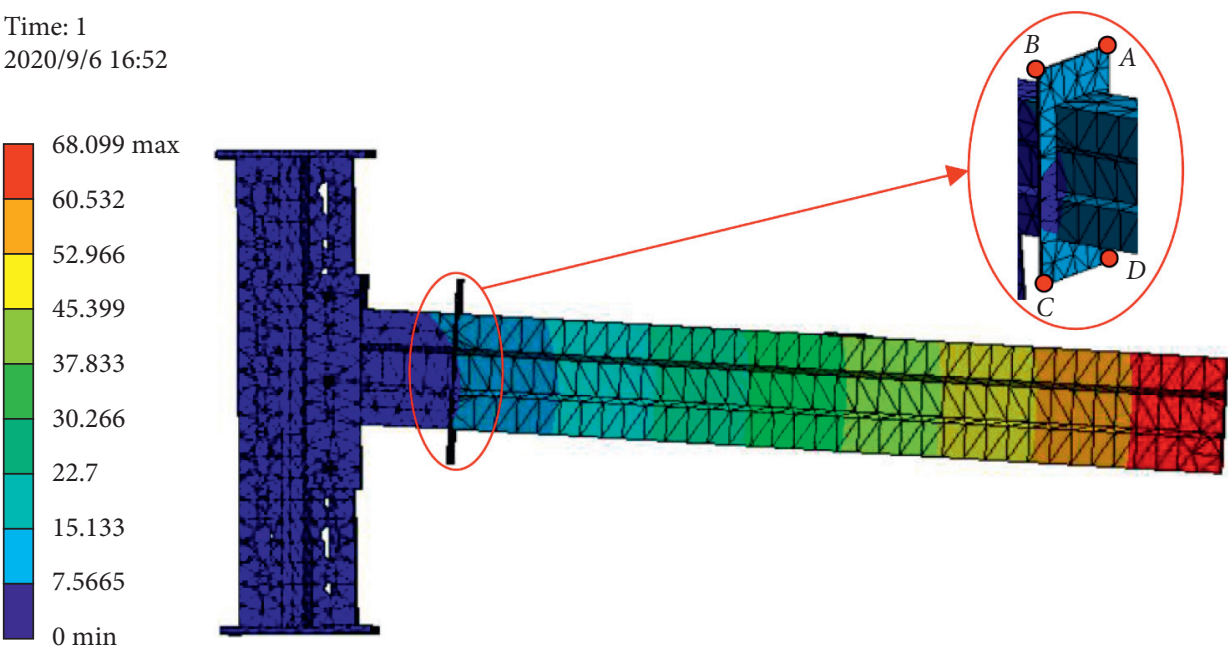

Figure 12: The result of finite element simulation.
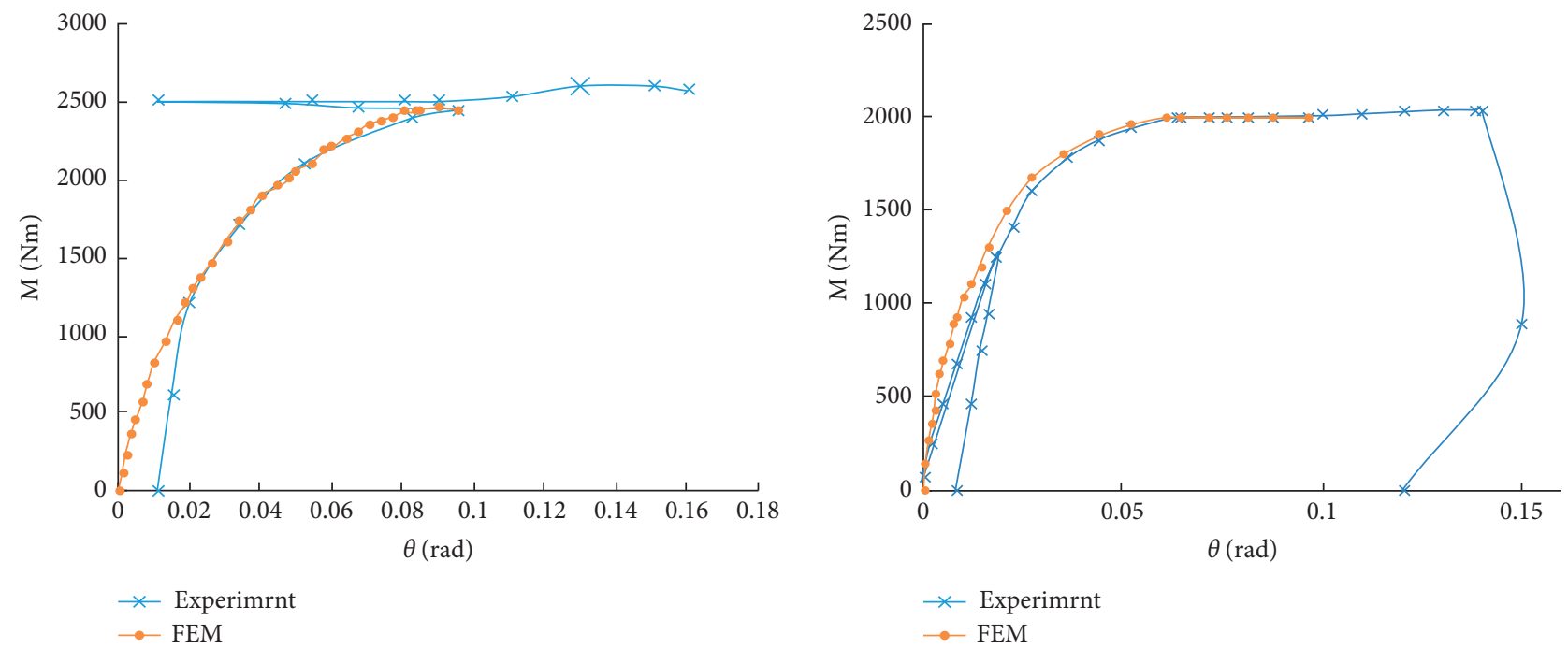

(a)
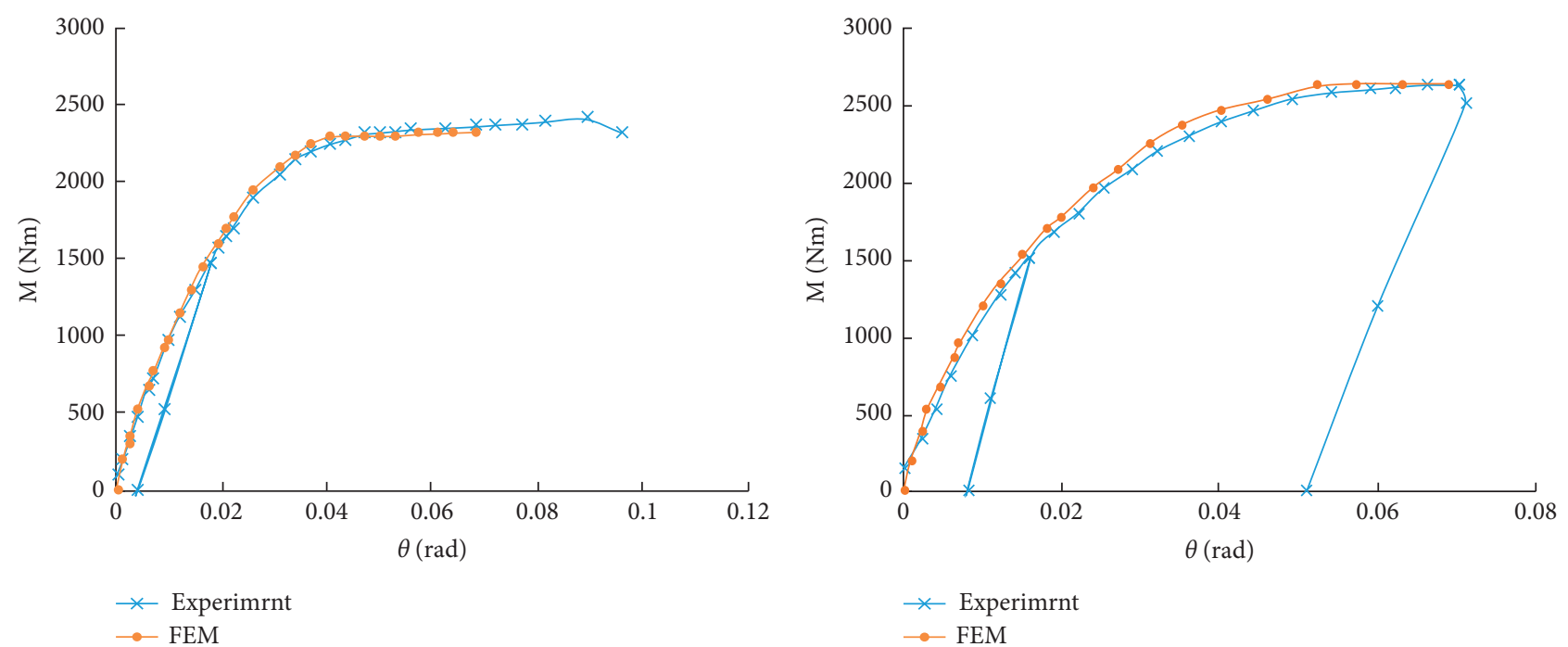

(c)

(d)

FIGURE 13: Comparison between experiment and finite element analysis. (a) Column: 90/77/2.0; beam/connector: 100/48-3 rivets. (b) Column: 100/90/2.5; beam/connector: 100/48-3 rivets. (c) Column: 100/100/2.0; beam/connector: 100/48-3 rivets. (d) Column: 120/94/2.0; beam/connector: $100 / 48-3$ rivets. 
TABLE 4: Comparison of failure modes between the experimental test and FEM.

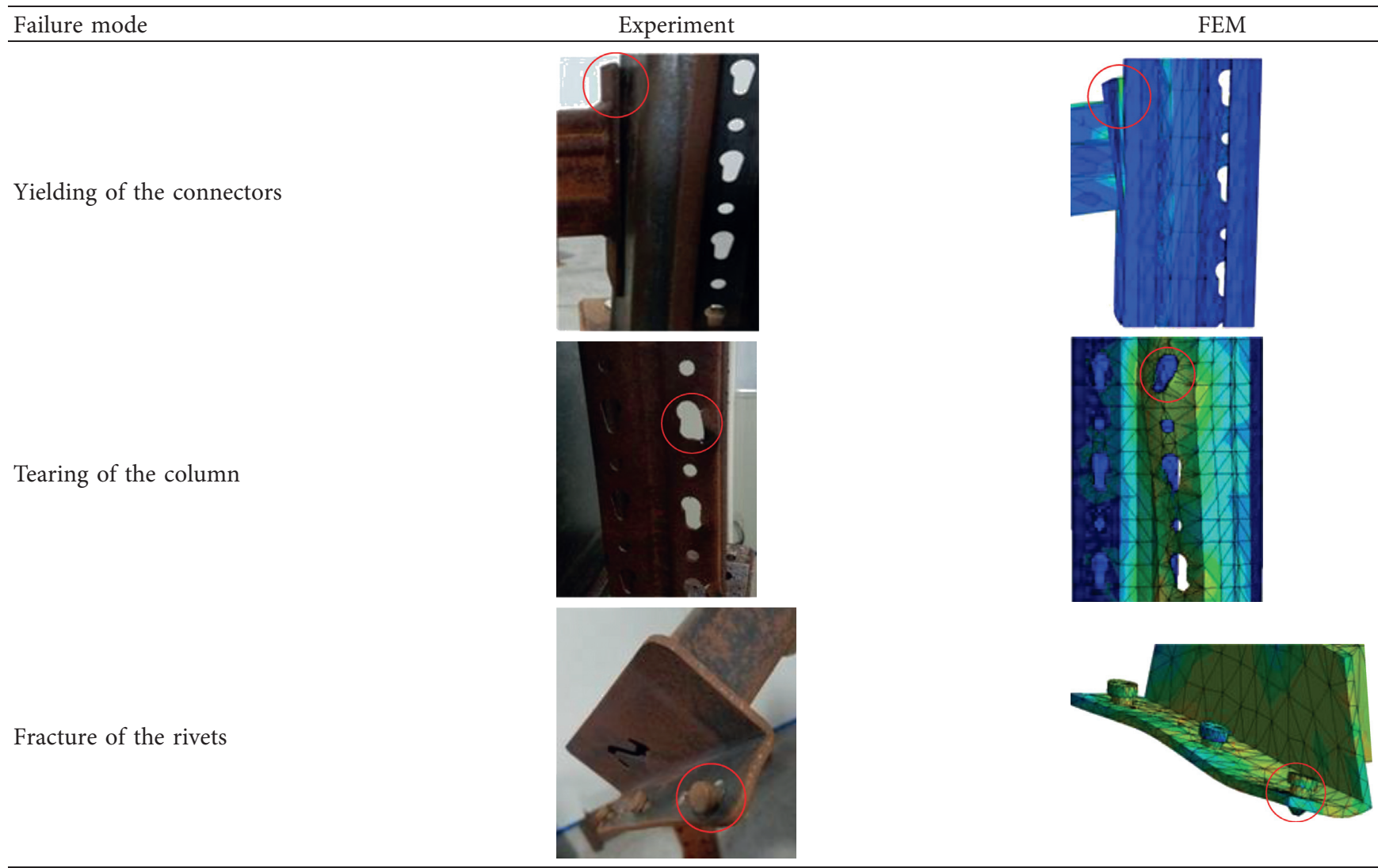

experimental behavior well as a whole, and the physical test on the BCCs can be replaced by the FE simulation from the perspective of engineering structure design. Consequently, with similar FE simulation method, 432 bending tests of beamto-column joints were carried out by selecting representative columns including M90 B, M100 A, and M100 B, which are the most widely used in industrial application. The detailed parameters and specific simulation data are shown in the Supplementary Material (available here).

\section{Empirical Studies}

To validate prediction performances on the SPR BCCs used by the proposed data-driven methods, some empirical cases are conducted in this study. This section first argues the mapping relationship of predictive model between the input data and output data. Then, it describes how the empirical cases were carried out. Finally, it provides a description of how the search for the parameter that achieves the best possible performance was made.

\section{SVM Regression Algorithms}

Support vector machines (SVMs) are based on principles of convex optimization and statistical learning theory proposed by Vapnik and Izmailov [36]. The main idea of the SVM regression algorithm is to estimate the output variable $y$ from original input data vector $x$ mapped into a higher-dimensional feature space through nonlinear transformation, and extract the information and regularity contained among the data. The SVM regression function is defined as

$$
y=f(x)=w^{T} \varphi(x)+b
$$

where $f(x)$ denotes the estimated value, $w$ the weight vector, $b$ a constant known as "bias", and $\varphi(x)$ a mapping function that maps the input data vector $x$ into a high-dimensional feature space. Minimized risk function can avoid overfitting and thereby improving the generalization capability while obtaining the weight vector $w^{T}$, as shown in

$$
\begin{array}{ll} 
& \min \frac{1}{2} w^{T} w+\gamma \sum_{t=1}^{T}\left(\zeta_{t}+\zeta_{t}^{*}\right) \\
\text { s.t. } \quad & w^{T} \varphi\left(x_{t}\right)+b \leq \phi+\zeta_{t}^{*}(i=1,2, \ldots, T), \\
& y_{t}-\left(w^{T} \varphi\left(x_{t}\right)+b\right) \leq \phi+\zeta_{t}(i=1,2, \ldots, T),
\end{array}
$$

where $\gamma$ is penalty parameter, and $\zeta_{\mathrm{t}}$ and $\zeta_{\mathrm{t}}^{*}$ are the sizes of the stated excess positive and negative deviations which are termed nonnegative "slack" variables, as shown in Figure 14. It is important to note that the feature $\varphi(x)$ need not be computed; rather, what is needed is the kernel function that has to satisfy Mercer's condition. Some of the mostly used kernels include polynomial, radial basis function (RBF), and sigmoid. In this study, RBF is used which is relatively simple and suitable for high-dimensional feature sets, as shown in 


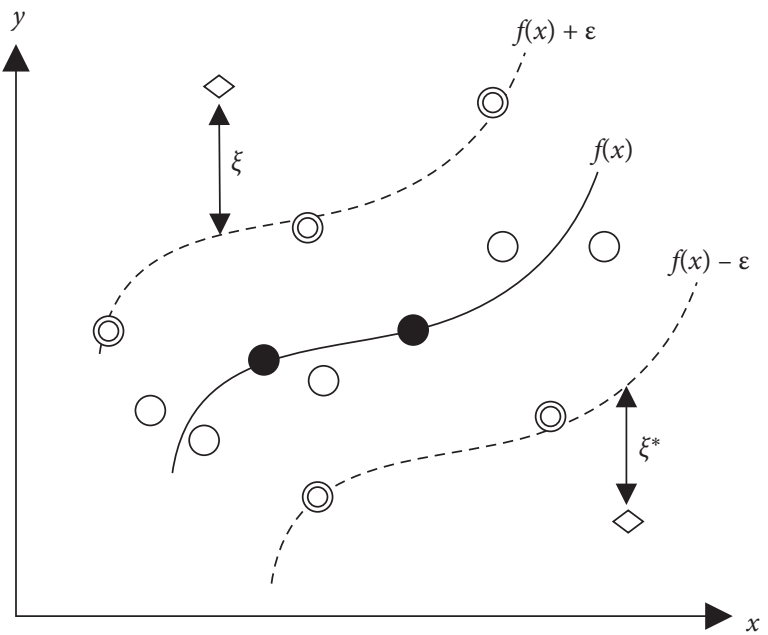

FIgURE 14: Diagram of support vector machine.

$$
K\left(x, x_{i}\right)=\exp \left[\frac{-\left|x-x_{i}\right|^{2}}{2 \sigma^{2}}\right]
$$

where $\sigma$ represents width of the RBF. Correct selection of kernel function parameters is critical to the performance and compensation accuracy of SVMs, which are described in detail in [37]. Some advances and more detailed description of SVM for regression can be found in [27, 36].

5.1. The Relational Mapping of Predictive Model Data. The construction of the prediction model only depends on the mapping relationship between input and output data, so the determination of input and output indexes of the prediction model plays an important role in the model construction. The only output of each prediction model based on data-driven method was the bending strength (BS) of boltless BCCs in our study. According to the properties of parameters, the performance parameters that may affect the BCCs are divided into two categories: structural parameters and assembly parameters. The influence of structural parameters such as column-related parameters, beam-related parameters, and connectorrelated parameters is considered, respectively, as the model inputs with reference to the existing analytical model $[14,38]$. On the other hand, according to the proposal in [39], the flexural rigidity of boltless BCC is largely affected by the different wielding positions between the connector and the stub beam. In fact, the boltless BCC is made up from the beam and the connector with the welding technology. The connector has an interference fit to the rivet, which makes the rivet in clearance fit with the column. Accordingly, in this paper, two additional assembly variables such as the beam position (BP) and the clearance between the connector and the column web (CL2) are also supposed to be utilized as the predictive model inputs so as to make it as close as possible to the practical application. The general relational mapping of predictive model data and its description are listed in Table 5.

\subsection{Model Train}

5.2.1. SVM Model Train. In this work, the regression prediction model of support vector machine is established by compiling relevant programs using the "Regression Learner App" in Matlab2017a [33]. A total of 432 sets of data were collected from finite element simulations of beam-column joints, of which 400 sets were used for model establishment and the remaining 32 sets were used for model result verification. The establishment of support vector machine prediction model includes the selection of verification methods, kernel functions, loss accuracy, and related parameters.

(1) Choose Verification Scheme. Choose a validation method to examine the predictive accuracy of the fitted models. Validation estimates model performance on new data, helps choose the best model, and protects against overfitting. A model that is too flexible and suffers from overfitting has a worse validation accuracy. Choosing a validation scheme before training any models can allow comparing all the models in the session using the same validation scheme. Each round of cross-validation involves randomly partitioning the original dataset into a training set and a testing set. The training set is then used to train a supervised learning algorithm, and the testing set is used to evaluate its performance. This process is repeated several times, and the average cross-validation error is used as a performance indicator. This paper uses the K-fold validation method provided in the "Regression Learner App."

(2) Selection of Kernel Function. The app can train regression support vector machines (SVMs) in Regression Learner. For greater accuracy on low-through medium-dimensional datasets, train an SVM model using "fitrsvm" function. The predictive results applying different core functions including Linear SVM, Quadratic SVM, Cubic SVM, Fine Gaussian SVM, Medium Gaussian SVM, and Coarse Gaussian SVM are shown in Table 6. By comparison with the root mean square error (RMSE), R-squared, mean squared error (MSE), and mean absolute error (MAE), the Cubic SVM is selected as the best core function of the model.

(3) Advanced SVM Options. The remaining advanced SVM options in Matlab App are demonstrated as follows. The box constraint is set to 4500 , the epsilon to 450 , and the kernel scale to 2. The model training results are shown in Figure 16.

After training a regression model, the predicted vs. simulated response plot (as shown in Figure 17) is used to check model performance, which is used to understand how well the regression model makes predictions for different response values. A perfect regression model has a predicted response equal to the true response, so all the points lie on a diagonal line. The vertical distance from the line to any point is the error of the prediction for that point. A good model has small errors, and so the predictions are scattered near the line.

The residual plot (as shown in Figure 18) is used to check model performance. The residual plot displays the difference between the predicted and simulated responses. Usually a good model has residuals scattered roughly symmetrically around zero. 


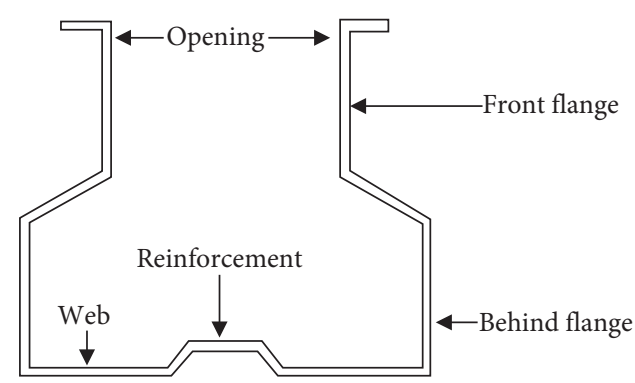

Figure 15: Section details of column.

TABLE 5: The input feature indicators.

\begin{tabular}{|c|c|c|c|}
\hline Related category & Indicators & Descriptions & Notes \\
\hline Column & $\begin{array}{l}\text { CT } \\
\text { CT1 }\end{array}$ & $\begin{array}{l}\text { The types of the columns } \\
\text { The column thickness }\end{array}$ & $\begin{array}{c}\text { On the basis of research by Shah et al. }[14,38] \text {, } \\
\text { as shown in Figure } 15\end{array}$ \\
\hline Beam & $\begin{array}{l}\text { BH } \\
\text { BW } \\
\text { BT }\end{array}$ & $\begin{array}{l}\text { The beam height } \\
\text { The beam width } \\
\text { The beam thickness }\end{array}$ & $\begin{array}{l}\text { Referring to the research by Zhao et al. [11], } \\
\text { the beam structure can be simplified to a rectangle for the } \\
\text { convenience of modeling and analysis, } \\
\text { as shown in Figure } 4\end{array}$ \\
\hline Connector & $\begin{array}{l}\mathrm{OPC} \\
\mathrm{NT} \\
\mathrm{CT} 2\end{array}$ & $\begin{array}{l}\text { The opening position of connector } \\
\text { The number of the rivets } \\
\text { The thickness of connector }\end{array}$ & $\begin{array}{l}\text { On the basis of research by Markazi et al. [39], } \\
\text { as shown in Figure } 4\end{array}$ \\
\hline $\begin{array}{l}\text { Assembly } \\
\text { parameters }\end{array}$ & $\begin{array}{l}\mathrm{BP} \\
\mathrm{CL}\end{array}$ & $\begin{array}{l}\text { The beam position } \\
\text { The clearance between the connector } \\
\text { and the column web }\end{array}$ & $\begin{array}{l}\text { This paper proposed assembly parameters as input indicators, } \\
\qquad \text { as shown in Figure } 5\end{array}$ \\
\hline
\end{tabular}

TABLE 6: Comparison of prediction models of different kernel functions.

\begin{tabular}{|c|c|c|c|c|}
\hline Name & RMSE & $R$-squared & MSE & MAE \\
\hline Linear SVM & 7306.48 & 0.21 & 53422823.02 & 4186.19 \\
\hline Quadratic SVM & 4597.41 & 0.68 & 21327775.39 & 3911.93 \\
\hline Cubic SVM & 1227.21 & 0.98 & 1522405.96 & 847.19 \\
\hline Fine Gaussian SVM & 6099.04 & 0.45 & 37151937.61 & 4036.13 \\
\hline Medium Gaussian SVM & 4577.70 & 0.69 & 20947018.98 & 2672.64 \\
\hline Coarse Gaussian SVM & 7490.49 & 0.17 & 56083875.77 & 4300.80 \\
\hline
\end{tabular}

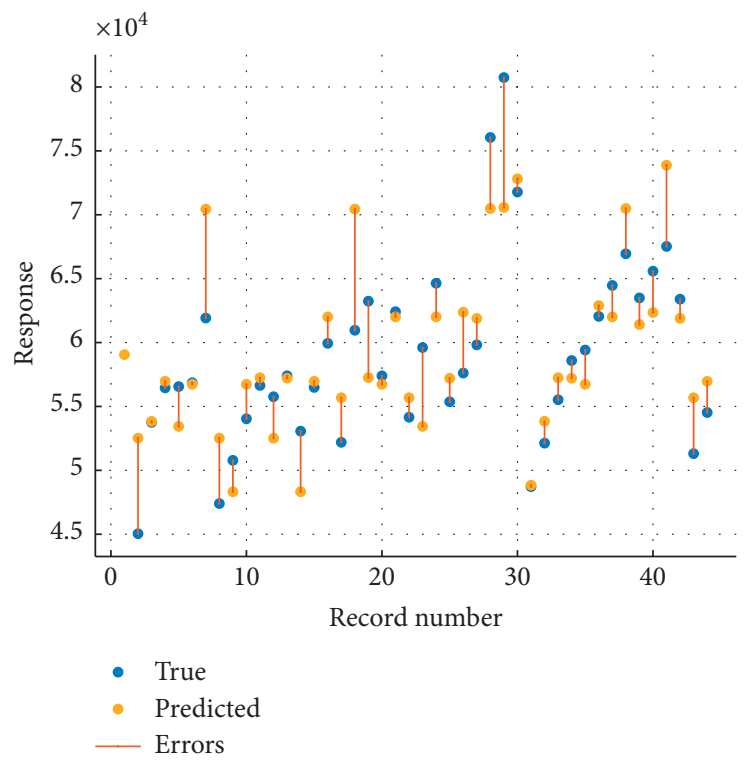

FIGURE 16: Response plot. 


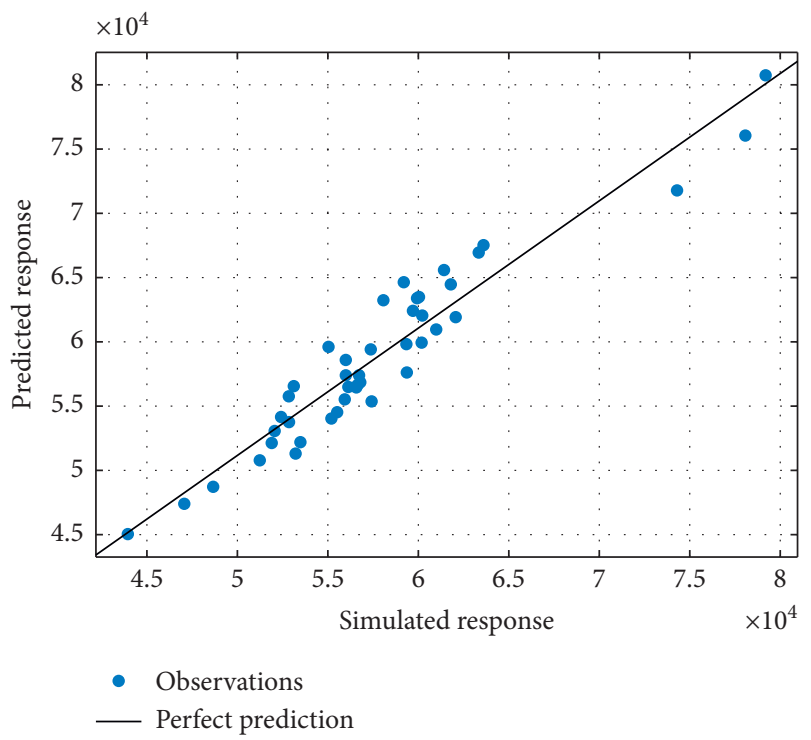

Figure 17: Predicted vs. simulated response plot.

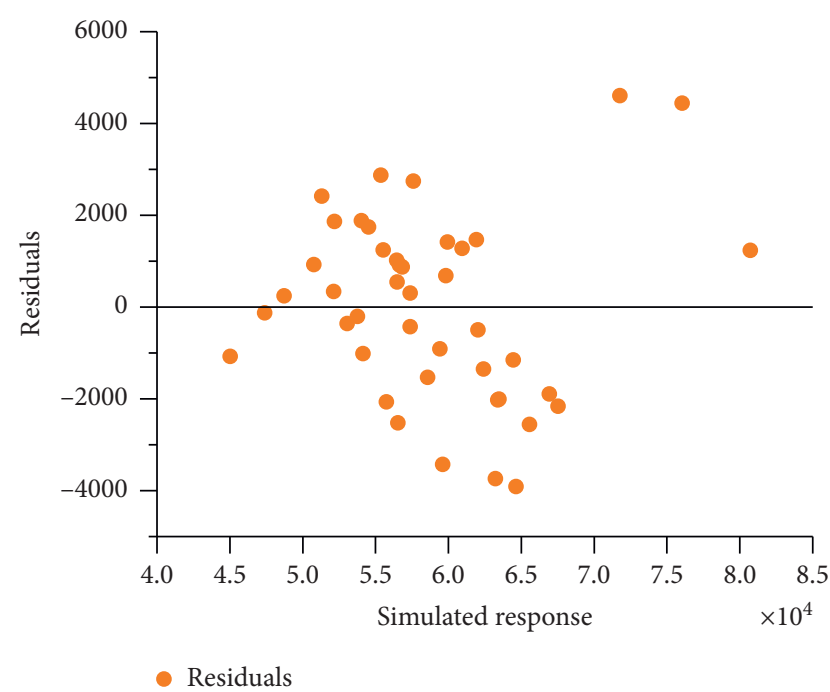

FIgURE 18: Residual plot.

5.2.2. ANN Model Train. Artificial neural network (ANN) is a powerful data-modeling tool that is able to capture and represent any kind of input-output relationships. BP is widely used in engineering because of its simple model and high prediction accuracy [40].

The design of BP model program adopts the artificial neural network app in Matlab2017a. The model training uses the same 400 sets of training data as SVM model. Similarly, the datasets from BCCs virtual test are divided into two groups of training data and testing data. The training process of the model includes the determination of hidden layer number, the selection of transfer function, and the preset number of neurons in hidden layer. The error of observation results can be modified by adjusting the above parameters, until the expected results are obtained.
TABLE 7: The selection of ANN model parameters.

\begin{tabular}{lc}
\hline Name & Parameters \\
\hline Hidden layer node number & 8 \\
Hidden layer number & 1 \\
Transfer function & logsig \\
\hline
\end{tabular}

TABLE 8: Comparison between the test values, SVM predicted values, and ANN predicted values.

\begin{tabular}{|c|c|c|c|c|c|}
\hline Number & Test & SVM & $\mathrm{AE}(\%)$ & ANN & $\mathrm{AE}(\%)$ \\
\hline 1 & 34870.00 & 35033.05 & 0.47 & 36607.54 & 4.98 \\
\hline 2 & 49890.00 & 51735.48 & 3.70 & 50863.15 & 1.95 \\
\hline 3 & 60640.00 & 60463.71 & 0.29 & 62736.40 & 3.46 \\
\hline 4 & 65170.00 & 65553.39 & 0.59 & 64236.76 & 1.43 \\
\hline \multicolumn{2}{|l|}{ MAE } & \multicolumn{2}{|c|}{40.7625} & \multicolumn{2}{|c|}{434.385} \\
\hline \multicolumn{2}{|l|}{ RMSE } & \multicolumn{2}{|c|}{950.06} & \multicolumn{2}{|c|}{1519.20} \\
\hline \multicolumn{2}{|l|}{ MAPE } & \multicolumn{2}{|c|}{$0.12 \%$} & \multicolumn{2}{|c|}{$1.19 \%$} \\
\hline \multicolumn{2}{|c|}{$\begin{array}{l}\text { Correlation } \\
\text { coefficient } R\end{array}$} & \multicolumn{2}{|c|}{0.9978} & \multicolumn{2}{|c|}{0.9959} \\
\hline \multicolumn{2}{|c|}{$R$-squared } & \multicolumn{2}{|c|}{0.9956} & \multicolumn{2}{|c|}{0.9919} \\
\hline \multicolumn{2}{|c|}{$\begin{array}{l}\text { Cases with an error } \\
\text { of more than } 3 \%\end{array}$} & \multicolumn{2}{|c|}{1} & \multicolumn{2}{|c|}{2} \\
\hline
\end{tabular}

In the light of Bishop's report, more than one hidden layer is usually not necessary. Therefore, the ANN architecture for thin-walled steel design has only one hidden layer. As proposed in the literature [41], the node number of hidden layers was obtained as 8 by

$$
s=\sqrt{0.43 m n+0.12 n^{2}+2.54 m+0.77 n+0.35+0.51},
$$

where $m$ is the number of neurons in the input layer and $n$ is the number of neurons in the output layer.

The BP network toolbox in Matlab2017a has a variety of transfer functions for modeling, including linear function, nonlinear function, and other error surface functions. In this paper, "logsig" is selected as the model transfer function, which is a differentiable logarithmic s-type transfer function, which maps the input range of neurons $(-\infty,+\infty)$ to the interval of $(0,+1)$, and its equation is

$$
\log \operatorname{sig}(n)=\frac{1}{1+e^{-n}}
$$

The detailed parameter settings of the ANN prediction model are summarized in Table 7.

5.3. Results and Discussion. After the establishment of the model, it still needs to be verified, so it is compared with the results of the four groups of mechanical properties tests, as shown in Table 8 . It can be seen that both SVM model and $\mathrm{BP}$ model are close to the test value, with mean absolute error (AE) of over 3\% and correlation coefficient $\mathrm{R}$ close to 1 . The accuracy of the model is preliminarily verified. Because the training set of the prediction model comes from the calculation results of the numerical model, the overall value 
TABLE 9: Comparison between the FEM values, SVM predicted values, and ANN predicted values.

\begin{tabular}{|c|c|c|c|c|c|}
\hline Number & FEM & SVM & $\mathrm{AE}(\%)$ & ANN & $\mathrm{AE}(\%)$ \\
\hline 1 & 43945.22 & 45042.03 & 2.50 & 48907.54 & 11.29 \\
\hline 2 & 52853.68 & 53755.41 & 1.71 & 52873.51 & 0.04 \\
\hline 3 & 56572.25 & 56453.72 & 0.21 & 56736.45 & 0.29 \\
\hline 4 & 53116.89 & 56553.71 & 6.47 & 54236.05 & 2.11 \\
\hline 5 & 56792.16 & 56853.3 & 0.11 & 57766.89 & 1.72 \\
\hline 6 & 62064.84 & 61920.47 & 0.23 & 62083.12 & 0.03 \\
\hline 7 & 47064.88 & 47399.29 & 0.71 & 45548.75 & 3.22 \\
\hline 8 & 51237.39 & 50781.86 & 0.89 & 49606.38 & 3.18 \\
\hline 9 & 55195.33 & 54033.37 & 2.11 & 54038.4 & 2.10 \\
\hline$\ldots$ & & & & & \\
\hline 31 & 51897.03 & 51306.61 & 3.59 & 50754.98 & 4.63 \\
\hline 32 & 55933.86 & 54525.76 & 1.78 & 55121.01 & 0.71 \\
\hline MAE & & & & & \\
\hline RMSE & & & & & \\
\hline MAPE & & & & & \\
\hline Correlatio & & & & & \\
\hline$R$-squared & & & & & \\
\hline $\begin{array}{l}\text { Cases with } \\
5 \%\end{array}$ & nore than & & & & \\
\hline
\end{tabular}

Note: the unit of bending strength is $\mathrm{kN} \mathrm{mm} / \mathrm{rad}$.

is higher than the experimental value. The final results are listed in Table 9, where "FEM," "SVM," and "ANN" refer to the finite element values, the SVM predicted values, and ANN predicted values, respectively. Statistical parameters, such as the mean absolute error (\%) and correlation coefficient $\mathrm{R}$ between the expected and real value, are used to judge the predictive power of the data-driven models. It is evident that the accuracy of all the predictive models is relatively high $(R>95 \%)$, while the SVM model, in terms of the mean absolute error and the ratio of the cases with more than $5 \%$ error, is lower than the ANN model. It is evident from Table 9 that the predictive power of the SVM model the predictive power of the SVM model is the better of the two models considered here.

\section{Conclusion}

Due to computational complexity and accuracy, the analytical expressions for the moment-rotation stiffness of thin-walled steel beam-to-column connections are not widely used for steel member design so far. In this paper, the $M-\theta$ behavior predictions from a novel data-driven model with the integrated experimental-FEM-SVM methodology are compared with those obtained from the traditional FEM and ANN model. It is noted that the data-driven model based on SVM technique is very efficient because the prediction performance is much closer to the physical test and FEM than those obtained from the ANN models. Here, we only demonstrate that, trained with the engineering datasets from experiment and simulation, the data-driven model is able to predict the $M-\theta$ behavior of different BCCs through self-learning, which can help engineers to make quick and effective decisions for complicated rack design. The results of our paper appear to be preliminary and limited to boltless BCCs situations, but it has been found that data-driven models for solving complex semirigid component design problems are very promising. Future research should focus on the following aspects: (1) expansion of the engineering analysis database to improve the flexibility of the data-driven model and then optimize the design configuration among a large number of beam-to-column joints; (2) development of new methodologies that can effectively explain the results of these apparently incomprehensible models. We believe that this research can be finally fused together with other pioneering analytic or experimental studies. With advancement of data mining and cloud computing techniques, many of the producers' subjective intuitions in steel pallet rack industry will finally be replaced by smart and friendly expert systems in the near future.

\section{Data Availability}

The detailed simulation data used to support the findings of this study are included within the supplementary data file. These data from FEM and tests are real and valid. They can be provided free of charge for those who need them.

\section{Conflicts of Interest}

The authors declare that there are no conflicts of interest regarding the publication of this paper.

\section{Acknowledgments}

This paper was financially supported by Technology Innovation Program of Shanghai Municipal Science and Technology Commission (17DZ2283800) and Songjiang District Industrial Development Special Fund on Demonstration Application Project (2018-01). The authors assure that the above-mentioned funding projects have been funded by the Shanghai Government to the authors' scientific research team of Donghua University. The funding expenditure complies with relevant regulations. 


\section{Supplementary Materials}

The detailed simulation and test data used to support the results of this study are provided in the Supplementary Material (Supplementary Materials)

\section{References}

[1] Đ. Jovanović, D. Žarković, V. Vukobratović, and Z. Brujić, "Hysteresis model for beam-to-column connections of steel storage racks," Thin-Walled Structures, vol. 142, pp. 189-204, 2019.

[2] S. N. R. Shah, N. H. Ramli Sulong, R. Khan, M. Z. Jumaat, and M. Shariati, "Behavior of industrial steel rack connections," Mechanical Systems and Signal Processing, vol. 70-71, pp. 725-740, 2016.

[3] R. Sousa, N. Batalha, and H. Rodrigues, "Numerical simulation of beam-to-column connections in precast reinforced concrete buildings using fibre-based frame models," Engineering Structures, vol. 203, Article ID 109845, 2020.

[4] EN 15512, Steel Static Storage Systems, European Technical Committee CEN/TC 344, European Specifications, Brussels, Belgium, 2009.

[5] RMI, "Specification for the design, testing and utilization of industrial steel storage racks, ANSI MH16.1-2012,” Technical Report, Rack Manufacturers Institute, Charlotte, NC, USA, 2012.

[6] AS/NZS 4084, Steel Storage Racking, Standards Australia/ Standards New Zealand, Sydney, Australia, 2012.

[7] M. Shariati, M. M. Tahir, T. C. Wee et al., "Experimental investigations on monotonic and cyclic behavior of steel pallet rack connections," Engineering Failure Analysis, vol. 85, pp. 149-166, 2018.

[8] A. Kanyilmaz, C. A. Castiglioni, G. Brambilla, and G. P. Chiarelli, "Experimental assessment of the seismic behavior of unbraced steel storage pallet racks," Thin-Walled Structures, vol. 108, pp. 391-405, 2016.

[9] P. A. Król, M. Papadopoulos-Woźniak, and J. Wójt, "Experimental investigation on shear strength of hooking-type beam-to-column joints, applied in one of high storage pallet racking systems," Procedia Engineering, vol. 91, pp. 232-237, 2014.

[10] P. Prabha, V. Marimuthu, M. Saravanan, and S. Arul Jayachandran, "Evaluation of connection flexibility in cold formed steel racks," Journal of Constructional Steel Research, vol. 66, no. 7, pp. 863-872, 2010.

[11] X. Zhao, T. Wang, Y. Chen, and K. S. Sivakumaran, "Flexural behavior of steel storage rack beam-to-upright connections," Journal of Constructional Steel Research, vol. 99, pp. 161-175, 2014.

[12] K. M. Bajoria, K. K. Sangle, and R. S. Talicotti, "Modal analysis of cold-formed pallet rack structures with semi-rigid connections," Journal of Constructional Steel Research, vol. 66, no. 3, pp. 428-441, 2010.

[13] M. L. Chisala, "Modelling $M-\theta$ curves for standard beamto-column connections," Engineering Structures, vol. 21, no. 12, pp. 1066-1075, 1999.

[14] X. Zhao, L. Dai, T. Wang, K. S. Sivakumaran, and Y. Chen, "A theoretical model for the rotational stiffness of storage rack beam-to-upright connections," Journal of Constructional Steel Research, vol. 133, pp. 269-281, 2017.

[15] F. Gusella, M. Orlando, and K. Thiele, "Evaluation of rack connection mechanical properties by means of the component method," Journal of Constructional Steel Research, vol. 149, pp. 207-224, 2018.

[16] I. Yaqoob, I. A. T. Hashem, A. Gani et al., "Big data: from beginning to future," International Journal of Information Management, vol. 36, no. 6, pp. 1231-1247, 2016.

[17] H. Salehi and R. Burgueño, "Emerging artificial intelligence methods in structural engineering," Engineering Structures, vol. 171, pp. 170-189, 2018.

[18] W.-Q. Song, C. Cattani, and C.-H. Chi, "Fractional Brownian motion and quantum-behaved particle swarm optimization for short term power load forecasting: an integrated approach," Energy, vol. 194, Article ID 116847, 2019, In press.

[19] Z. M. Yaseen, M. T. Tran, S. Kim, T. Bakhshpoori, and R. C. Deo, "Shear strength prediction of steel fiber reinforced concrete beam using hybrid intelligence models: a new approach," Engineering Structures, vol. 177, pp. 244-255, 2018.

[20] F. Sena Cardoso and K. J. R. Rasmussen, "Finite element (FE) modelling of storage rack frames," Journal of Constructional Steel Research, vol. 126, pp. 1-14, 2016.

[21] Y.-J. Cha, W. Choi, and O. Büyüköztürk, "Deep learningbased crack damage detection using convolutional neural networks," Computer-Aided Civil and Infrastructure Engineering, vol. 32, no. 5, pp. 361-378, 2017.

[22] Z. Wang and Y. Cha, "Automated damage-sensitive feature extraction using unsupervised convolutional neural networks," in Proceedings of the Sensors and Smart Structures Technologies for Civil, Mechanical, and Aerospace Systems 2018, vol. 10598, Article ID 105981J, March 2018.

[23] A. Santos, E. Figueiredo, M. F. M. Silva, C. S. Sales, and J. C. W. A. Costa, "Machine learning algorithms for damage detection: kernel-based approaches," Journal of Sound and Vibration, vol. 363, pp. 584-599, 2016.

[24] R. Langone, E. Reynders, S. Mehrkanoon, and J. A. K. Suykens, "Automated structural health monitoring based on adaptive kernel spectral clustering," Mechanical Systems and Signal Processing, vol. 90, pp. 64-78, 2017.

[25] R. Ghiasi and M. R. Ghasemi, "An intelligent health monitoring method for processing data collected from the sensor network of structure," Steel \& Composite Structures, vol. 29, pp. 703-716, 2018.

[26] V. N. Vapnik, Statistical Learning Theory, Wiley, New York, NY, USA, 2nd edition, 1998.

[27] P. Debnath and A. K. Dey, "Prediction of bearing capacity of geogrid-reinforced stone columns using support vector regression," International Journal of Geomechanics, vol. 18, no. 2, Article ID 04017147, 2018.

[28] W. Chen, J. Zhang, M. Gao, and G. Shen, "Performance improvement of 64-QAM coherent optical communication system by optimizing symbol decision boundary based on support vector machine," Optics Communications, vol. 410, pp. 1-7, 2018.

[29] F. De Boissieu, B. Sevin, T. Cudahy et al., "Regolith-geology mapping with support vector machine: a case study over weathered Ni-bearing peridotites, New Caledonia," International Journal of Applied Earth Observation and Geoinformation, vol. 64, pp. 377-385, 2018.

[30] J. Luo, X. Yan, and Y. Tian, "Unsupervised quadratic surface support vector machine with application to credit risk assessment," European Journal of Operational Research, vol. 280, no. 3, pp. 1008-1017, 2020.

[31] K. E. Pilario, M. Shafiee, Y. Cao, L. Lao, and S.-H. Yang, "A review of kernel methods for feature extraction in nonlinear process monitoring," Processes, vol. 8, no. 1, p. 24, 2019. 
[32] A. Kozłowski and L. Ślęczka, "Preliminary component method model of storage rack joint," in Proceedings of the Connections in Steel Structures V, pp. 253-262, Amsterdam, Netherlands, June 2004.

[33] MathWorks, MATLAB (R2017a) User Guide, MathWorks, Natick, MA, USA, 2017, http://www.mathworks.com/ support.

[34] N. Talebian, B. P. Gilbert, N. Baldassino, and H. Karampour, "Factors contributing to the transverse shear stiffness of bolted cold-formed steel storage rack upright frames with channel bracing members," Thin-Walled Structures, vol. 136, pp. 50-63, 2019.

[35] EN 10002-1, Metallic Materials-Tensile Testing-Part 1: Method of Test at Ambient Temperature, European Committee for Standardization (CEN), Brussels, Belgium, 2001.

[36] V. Vapnik and R. Izmailov, "Knowledge transfer in SVM and neural networks," Annals of Mathematics and Artificial Intelligence, vol. 81, no. 1-2, pp. 3-19, 2017.

[37] L. Olatomiwa, S. Mekhilef, S. Shamshirband, K. Mohammadi, D. Petković, and C. Sudheer, "A support vector machinefirefly algorithm-based model for global solar radiation prediction," Solar Energy, vol. 115, pp. 632-644, 2015.

[38] S. N. R. Shah, N. H. Sulong-Ramli, N. H. Sulong, R. Khan, and M. Z. Jumaat, "Structural performance of boltless beam end connectors," Advanced Steel Construction, vol. 13, no. 2, pp. 144-159, 2017.

[39] F. D. Markazi, R. G. Beale, and M. H. R. Godley, "Numerical modelling of semi-rigid boltless connectors," Computers \& Structures, vol. 79, no. 26-28, pp. 2391-2402, 2001.

[40] A. K. Abbas, N. A. Al-haideri, and A. A. Bashikh, "Implementing artificial neural networks and support vector machines to predict lost circulation," Egyptian Journal of Petroleum, vol. 28, no. 4, pp. 339-347, 2019.

[41] K.-Y. Dong and W.-D. Yu, "A worsted yarn virtual production system based on BP neural network," Journal of Donghua University, vol. 21, no. 4, pp. 34-37, 2004. 